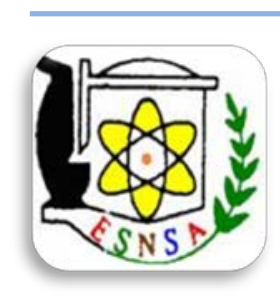

Arab Journal of Nuclear Sciences and Applications

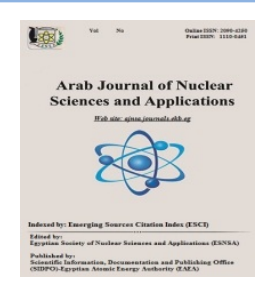

(ESNSA)

\title{
Neutronic Analysis of Heavy Water Application in HPLWR Emergency Core Cooling System
}

\author{
S. Tashakor \\ Department of Renewable Energy, Shiraz Branch, Islamic Azad University, Shiraz, Iran
}

\begin{abstract}
Received $26^{\text {th }}$ Oct 2017 Since 2002 a generation IV nuclear energy system development project has been initiated to enhance the Accepted $14^{\text {th }}$ Jan 2018 future role of nuclear energy systems. Challenging technology goals for generation IV nuclear reactor systems were defined in 4 areas: sustainability, economics, safety and reliability and proliferation resistance. Light water reactors at supercritical pressure, currently under design, are the new generation of nuclear reactors. The high-performance light water reactor (HPLWR) is the European version of the supercritical-pressure water cooled reactor (SCWR). The aim of the present study is to conduct a reliability analysis of heavy water emergency core cooling system (ECCS) (instead of light water ECCS) in HPLWRs during LOCA (loss of coolant accident) through neutronics calculations and applied feedback.. Reliability analysis (neutronic calculations) is performed using WIMS and CITATION codes. Changes in neutronic parameters, such as neutron cross-sections, effective multiplication factor and power peaking factor during LOCA, are discussed by injecting different concentrations of the heavy water coolant by ECCS.
\end{abstract}

Keywords: HPLWR/ ECCS/ Heavy Water/ Neutronic Analysis

\section{Introduction}

The High Performance Light Water Reactor (HPLWR) is a Supercritical Pressure Water Cooled Reactor (SCWR) design, proposed and investigated within an EU-Project [1]. The main characteristic of the supercritical water reactor concept is its operating pressure above the critical point of water (22.1 MPa, $374 \mathrm{oC}$ ) [2]. This gives many advantages compared to the current light water reactors (LWR). This includes: an increase in thermal efficiency due to higher operating temperature (44\% against 33-35\%forLWR), no boiling crisis given the essentially single-phase nature of supercritical water, and a better economics for the absence of steam separators and dryers as well as steam generators and smaller containment building [3]. Ishiwatari et al. [4] have presented safety characteristics of the super LWR design concept. Lee et al. developed a LOCA analysis code for supercritical-pressure light water cooled reactors [5]. Neutronic and Thermal hydralic analysis of HPLWR fuel assembly cluster has been performed by Tashakor et al [6,7]. Tashakor et al [8] presented an axial enrichment profile in advance nuclear energy power plant at supercriticalpressures. Neutronic analysis of semi-heavy water in VMHWR has been presented by Tashakor $[9,10]$, and the results show that use of semi-heavy water in VMHWRs coolant channels will lead to optimal fuel burn up and reactor performance. Heavy water (D2O) is $10 \%$ heavier than ordinary water and has a neutron moderating ratio 80 times higher than ordinary water. Although the absorption cross-section of heavy water is much less than that of light water, the former involves a lower diffusion constant.

Corresponding Author: saman.tashakor@yahoo.com

DOI: 10.21608 /ajnsa.2017.1940.1006

(C) Scientific Information, Documentation and Publishing Office (SIDPO)-EAEA 
ECCS are designed to guarantee the safe shut down of a nuclear reactor during an accident. ECCS supply makeup water to cool the reactor in the event of a loss of coolant from the reactor cooling system. This cooling is needed to remove the decay heat still in the reactor's fuel after the reactor is shutdown. The ECCS allows the plant to respond to a variety of accident conditions and additionally introduce redundancy so that the plant can be shut down even with one or more subsystem failures. The emergency core cooling systems consist of high pressure and low pressure systems. The high pressure systems are the high pressure coolant injection (HPCI) system and the automatic depressurization system (ADS). The low pressure systems are the low pressure coolant injection (LPCI) mode of the residual heat removal system and the core spray (CS) system. In this research, neutronic performance of using heavy water in the HPLWRs emergency core cooling system (ECCS) is done by coupling WIMS-D5 [11] and CITATION-LDI2 [12] codes.

\section{Methods and Materials}

The HPLWR is one of the six nuclear reactor systems of Generation IV International Forum (GIF). The operating pressure and core inlet/outlet temperatures are $25 \mathrm{MPa}$ and $280 / 500{ }^{\circ} \mathrm{C}$, respectively. Fuel assembly configuration has been proposed by Tashakor et al. [6,7]. A view of the fuel assembly in HPLWR is shown in Fig. (1) The fuel assembly consists of 40 fuel rods arranged in square lattice. The design specification of the fuel assembly is shown in Table (1).

The emergency core cooling system (ECCS) of the HPLWR consists of the auxiliary feed water system (AFS), low pressure core injection system (LPCI) and automatic depressurization system (ADS). The purpose of this research is to investigate the neutronic behavior of HPLWR following the use of heavy water through an emergency coolant system in the reactor core. When LOCA takes place, the emergency coolant systems enter the line, and depending on the degree of the break, water is pumped at different rates into the reactor core to guarantee its coolingdown. This study assumed that instead of ordinary water used in prevalent systems for the purpose injection, heavy water could alternatively serve as the coolant.

\begin{tabular}{lcc}
\multicolumn{1}{c}{ Table (1): HPLWR fuel assembly specification } \\
\hline Puemeters & Unit & Value \\
\hline Cladding material & - & $\mathrm{UO}_{2}$ \\
Outer cladding diameter & - & Stainless steel \\
Inner cladding diameter & $\mathrm{mm}$ & 8 \\
Fuel pellet outer diameter & $\mathrm{mm}$ & 7 \\
Active height & $\mathrm{mm}$ & 0.69 \\
Pitch of fuel rods & $\mathrm{mm}$ & 4200 \\
Number of cluster fuel rods & $\mathrm{mm}$ & 9.2 \\
Number of assembly fuel rods & - & 360 \\
Gap between fuel rods and box wall & $\mathrm{mm}$ & 40 \\
Fluid pressure & $\mathrm{MPa}$ & 25 \\
Inner side length of moderator tube & $\mathrm{mm}$ & 26.2 \\
Wall thickness of moderator tube & $\mathrm{mm}$ & 0.3 \\
Fuel enrichment & - & $4-5 \%$ \\
Gadolinia concentration (wt\%) & & 4 \\
Total power of fuel assembly & $\mathrm{MW}$ & 25.80 \\
Total coolant mass flow rate & $\mathrm{kg} / \mathrm{s}$ & 11.8544 \\
Mass flow rate in the moderator & $\mathrm{kg} / \mathrm{s}$ & 0.07784 \\
tube & $\mathrm{kg} / \mathrm{s}$ & 0.1556 \\
Mass flow rate in the assembly gap & & \\
\hline
\end{tabular}

The computer codes WIMS-D4 and CITATION were used for neutronic analysis. The codes have jointly been used for neutronic calculation of different thermal power reactors. WIMS-D4 code has been used for cell calculation of fuel assembly. Winfrith Improved Multigroup Scheme version-D (WIMS-D4) is one of the widely used deterministic computational tools for basic reactor physics lattice cell calculations. It can deal with a variety of geometries and solve the energy dependent transport equation with varying degrees of approximations by different methods using one dimensional modeling. Using the codes, one can calculate parameters, such as diffusion coefficients, absorption and fission cross sections and scattering matrix for given number of energy groups $[6,10,11]$. The effective cross-section and group constants calculated by WIMS code for various regions of the fuel assembly along with the fuel assembly geometry and boundary condition are provided as input data to the CITATION code to calculate effective multiplication factor. This code (CITATION) uses the finite-difference representation of diffusion theory in three dimensions with arbitrary group-to-group 
scattering. The neutron flux-eigenvalue problems are solved by direct iteration to determine the multiplication factor or the nuclide densities required for a critical system $[12,13]$.

Due to symmetry, a quarter of a fuel assembly is considered and cell calculations are done for 12 fuel rods in the assembly. Since the fluid temperature is not constant throughout the assembly, the assembly is divided into 45 mesh points in height. In each region, the average temperature and modified fluid density are calculated accordingly. [6,7].

After calculation of the fuel rod group constants, by inserting these data in CITATION input file (card 008-Macroscopic cross section) the thermal power distribution in each fuel rod is analyzed. In the CITATION code, the assembly with the moderator channel and assembly gap is modeled via a $9 \times 9$ lattice (Fig. 2). Table (2) illustrates the physical proprieties of heavy water compared to the light water.

\section{Results and discussion}

Injecting heavy water into HPLWR reactors at the time of LOCA by ECCS would result in a change in neutron cross-sections. Figures 3-6 illustrate, scattering cross-section, absorption cross-section, constant diffusion changes and diffusion length of thermal neurons with different concentrations of heavy water in the moderator. As Figure 3 shows, as the concentration of heavy water increases in the moderator channel, scattering cross-section will be decreased, which is due to the lower scattering cross-section of heavy water compared to that of light water. However, a decrease in scattering cross-section would also continuously increase neutrons diffusion. By increasing the volume percent of heavy water, the absorption cross-section of thermal neutrons will be decreased, and this is attributed to the lower absorption cross-section of heavy water. This decrease of the absorption cross-section would lead neutrons to pass a longer distance to be converted into a thermal state, which is a phenomenon increasing neutrons' thermal diffusion length in the reactor core.
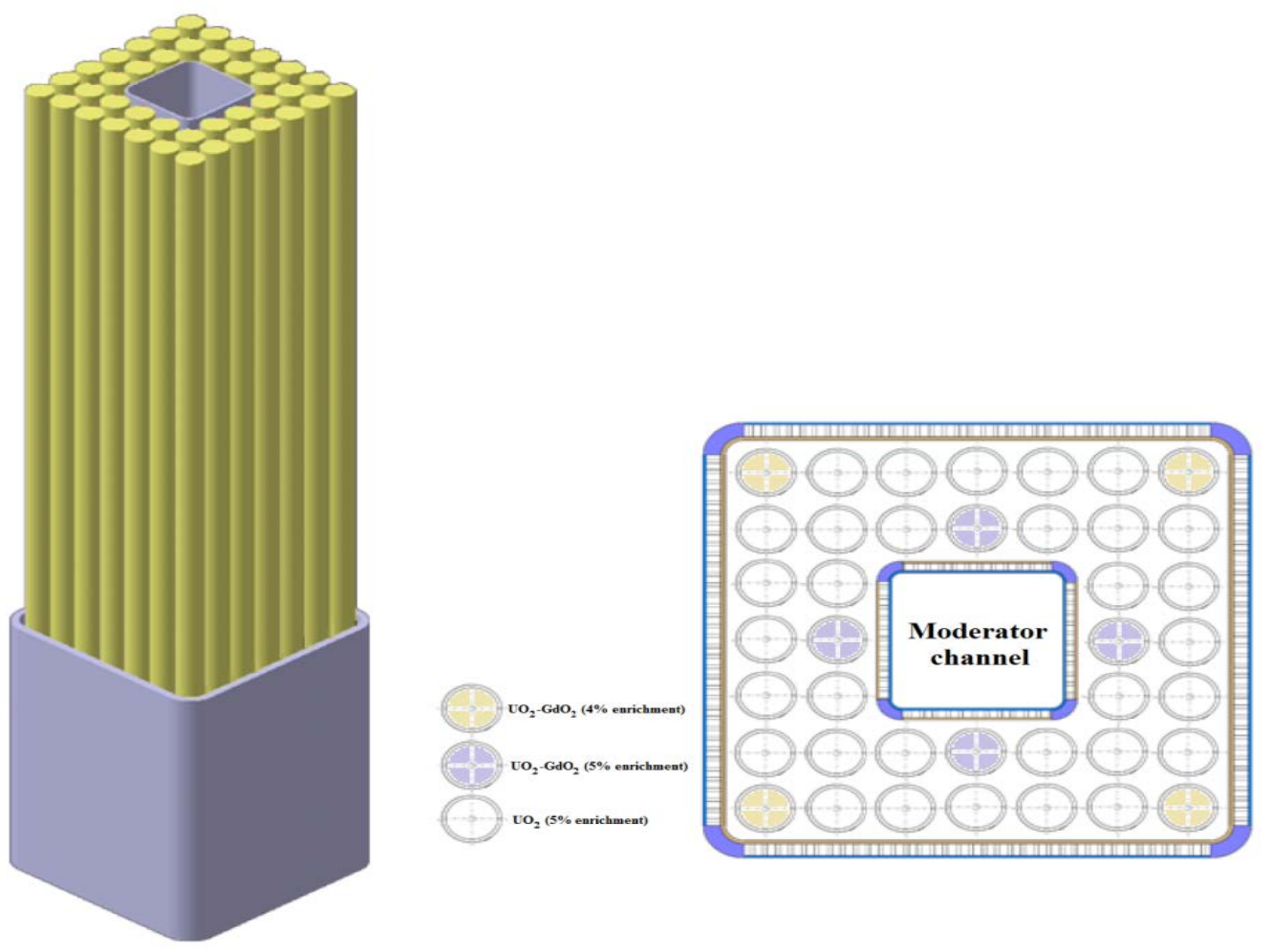

Fig. (1): HPLWR fuel assembly 


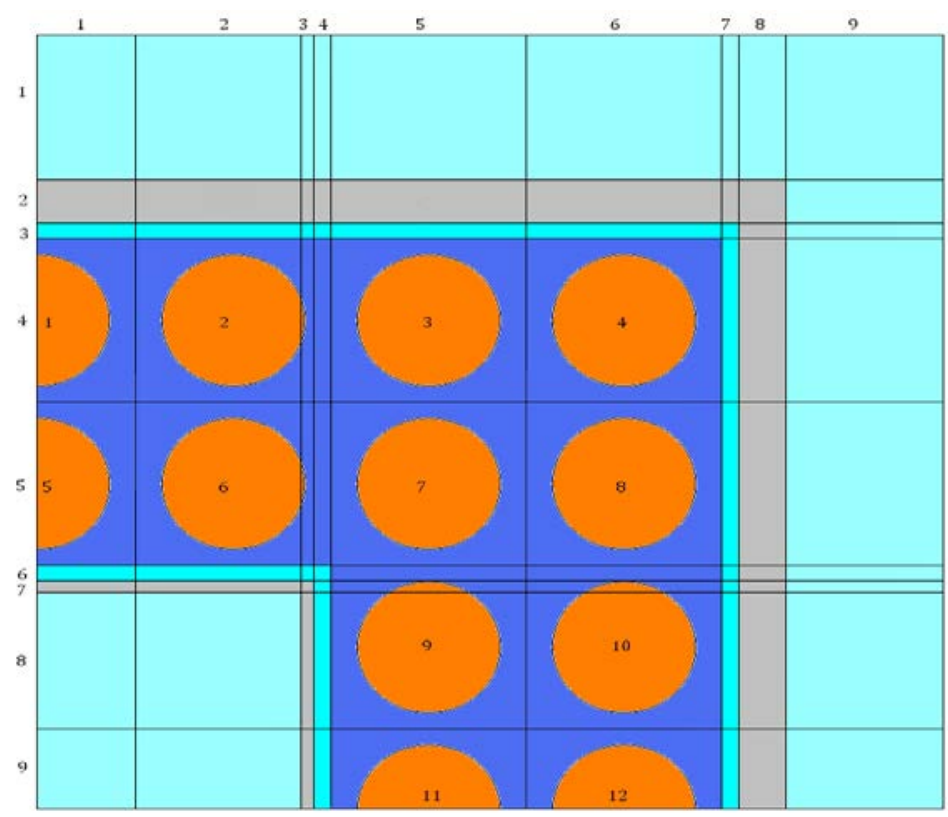

Fig. (2): Meshing process in the assembly using CITATION code

Table (2): Heavy water physical properties comparison to light water [14]

\begin{tabular}{lcc}
\hline Properties & $\begin{array}{c}\mathbf{H}_{\mathbf{2}} \mathbf{O} \\
\text { (Light water) }\end{array}$ & $\begin{array}{c}\mathbf{D}_{\mathbf{2}} \mathbf{O} \\
\text { (Heavy water) }\end{array}$ \\
\hline Freezing point $\left({ }^{\circ} \mathrm{C}\right)$ & 0.0 & 3.82 \\
Boiling point $\left({ }^{\circ} \mathrm{C}\right)$ & 100.0 & 101.4 \\
Density at STP $(\mathrm{g} / \mathrm{mL})$ & 0.9982 & 1.1056 \\
Temp. of maximum density $\left({ }^{\circ} \mathrm{C}\right)$ & 3.98 & 11.6 \\
Dynamic viscosity $\left(\right.$ at $\left.20{ }^{\circ} \mathrm{C}, \mathrm{mPa} \cdot \mathrm{s}\right)$ & 1.0016 & 1.2467 \\
Surface tension $\left(\right.$ at $\left.25^{\circ} \mathrm{C}, \mathrm{N} / \mathrm{m}\right)$ & 0.07198 & 0.07187 \\
Heat of fusion $(\mathrm{kJ} / \mathrm{mol})$ & 6.00678 & 6.132 \\
Heat of vaporization $(\mathrm{kJ} / \mathrm{mol})$ & 40.657 & 41.521 \\
\hline
\end{tabular}

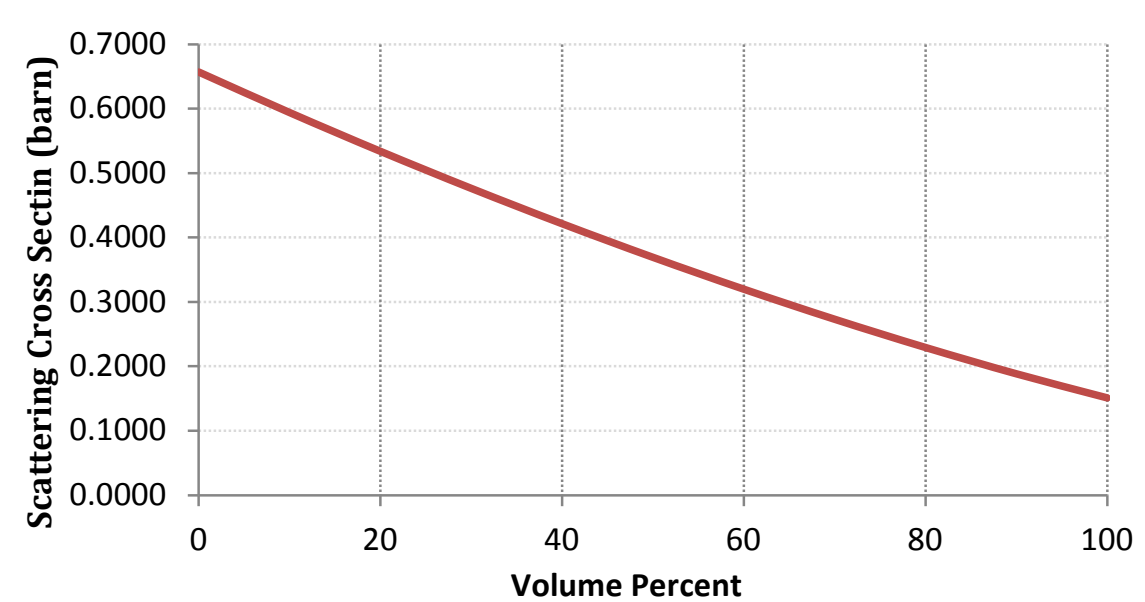

Fig. (3): Changes of the scattering cross section in different concentrations of heavy water 


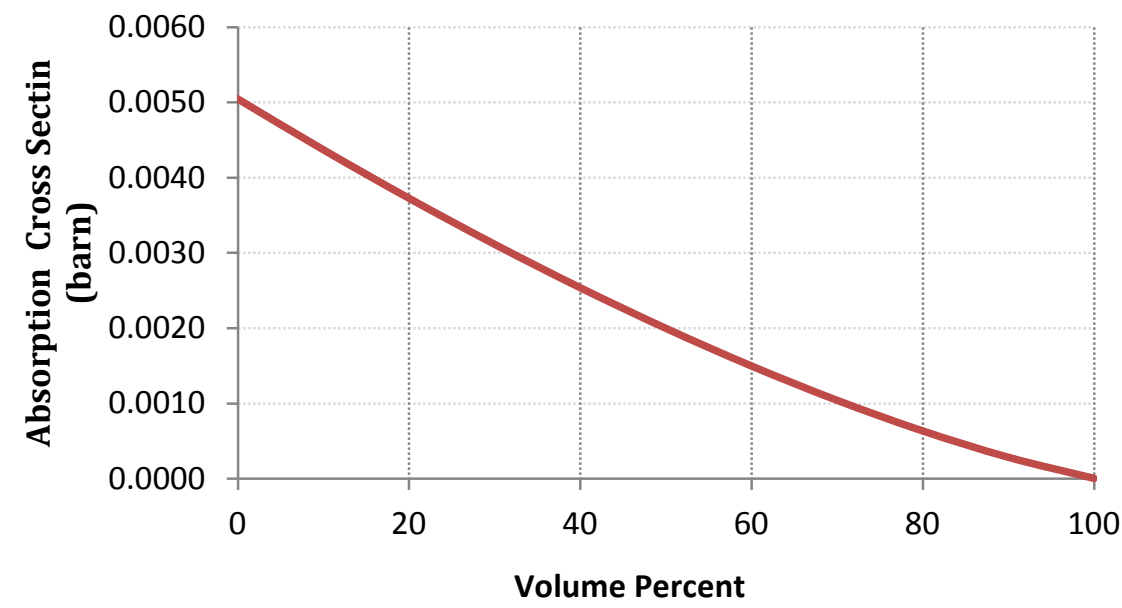

Fig. (4): Changes of the absorption cross section in different concentrations of heavy water

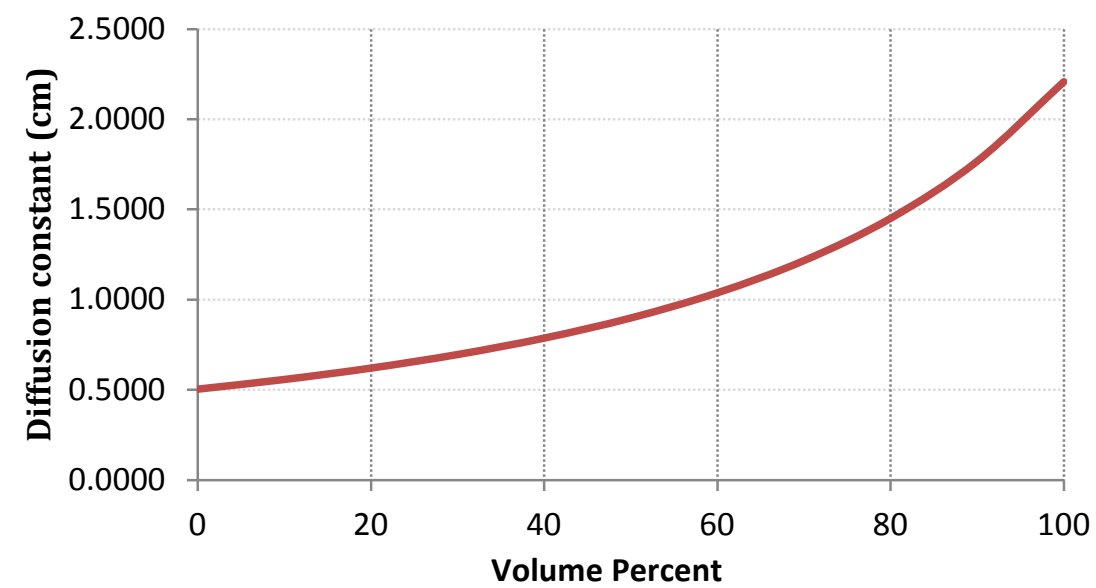

Fig. (5): Changes of the diffusion constant in different concentrations of heavy water

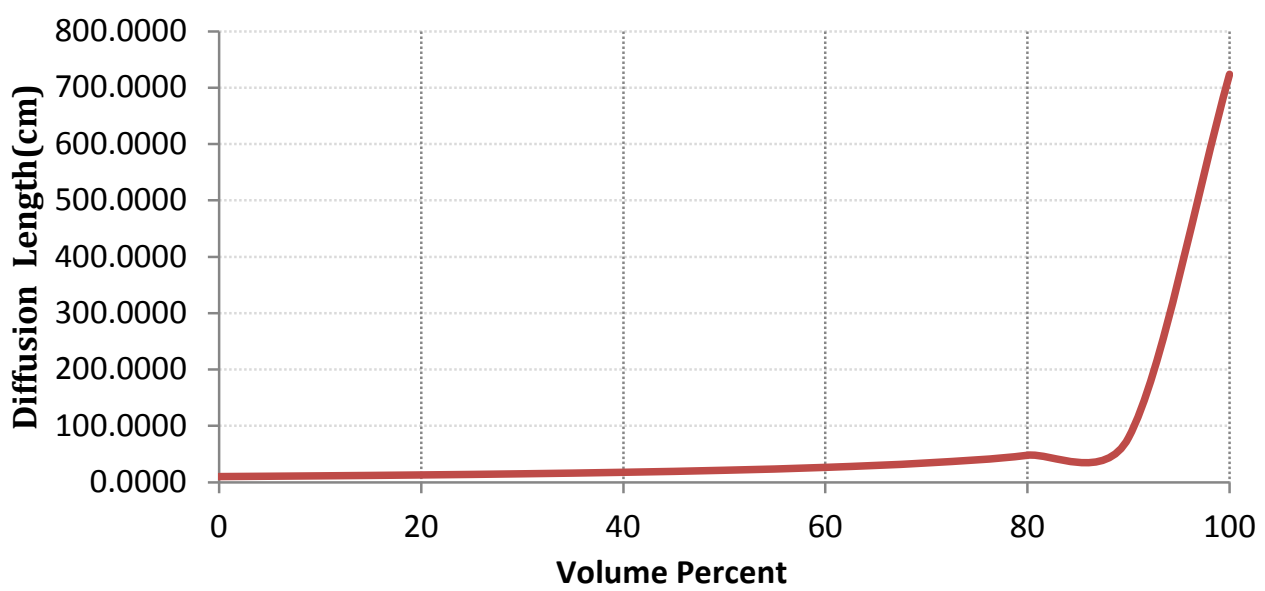

Fig. (6): Changes of the diffusion length in different concentrations of heavy water 
Figures( 7 and 8) show changes taking place in the absorption cross-section and fission in the fuel, in the form of a function of heavy water concentration respectively. Figures (7 and 8) illustrate clearly that the increase in heavy water concentration in the coolant leads to a sharp decrease in the absorption and fission crosssections

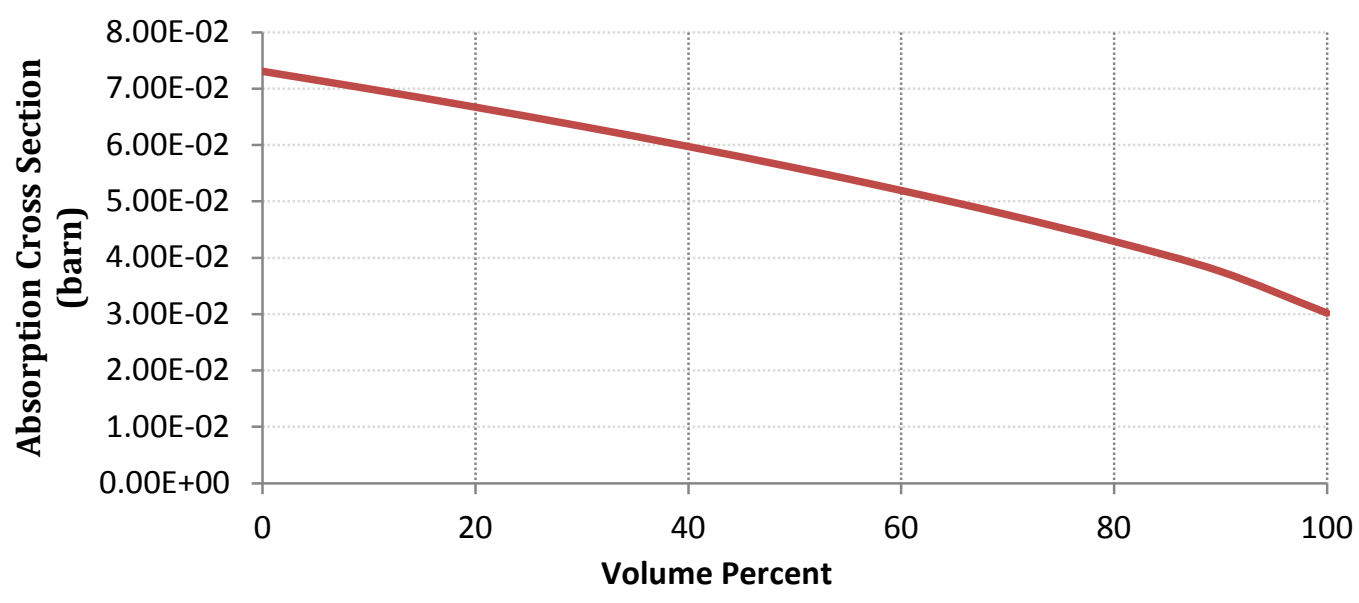

Fig. (7): Changes of the fuel absorption cross section in different concentrations of heavy water

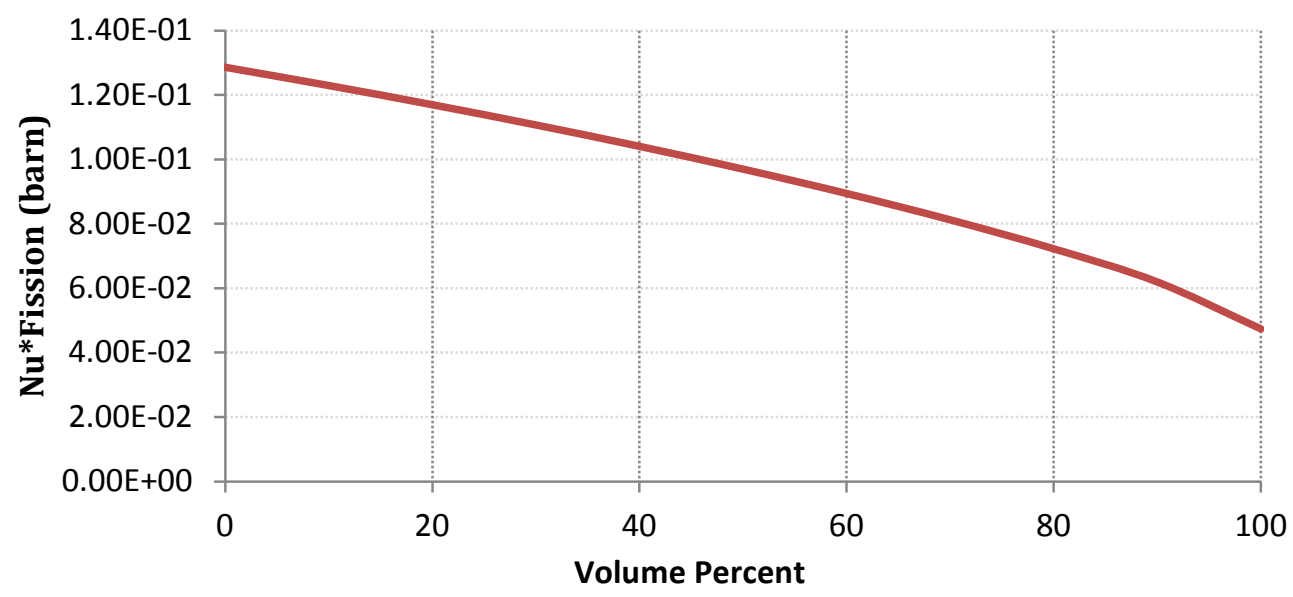

Fig. (8): Changes of the fuel fission cross section in different concentrations of heavy water

Figures (9 and 10) depict effective multiplication factor changes as well as the reactivity injected into the reactor core for different heavy water concentrations respectively. Results related to effective multiplication factor show that an increase in heavy water concentration would lead to a decreased effective multiplication factor. This impact might have been derived from modifications in absorption and scattering crosssections due to injection heavy water into the coolant. This phenomenon led to the hardening of neutron spectra and shifted them towards neutrons with higher energies. In case of increased hardening of neutron spectra, neutrons would be more likely to escape, and as a consequence of this process, negative reactivity was injected into the system. 


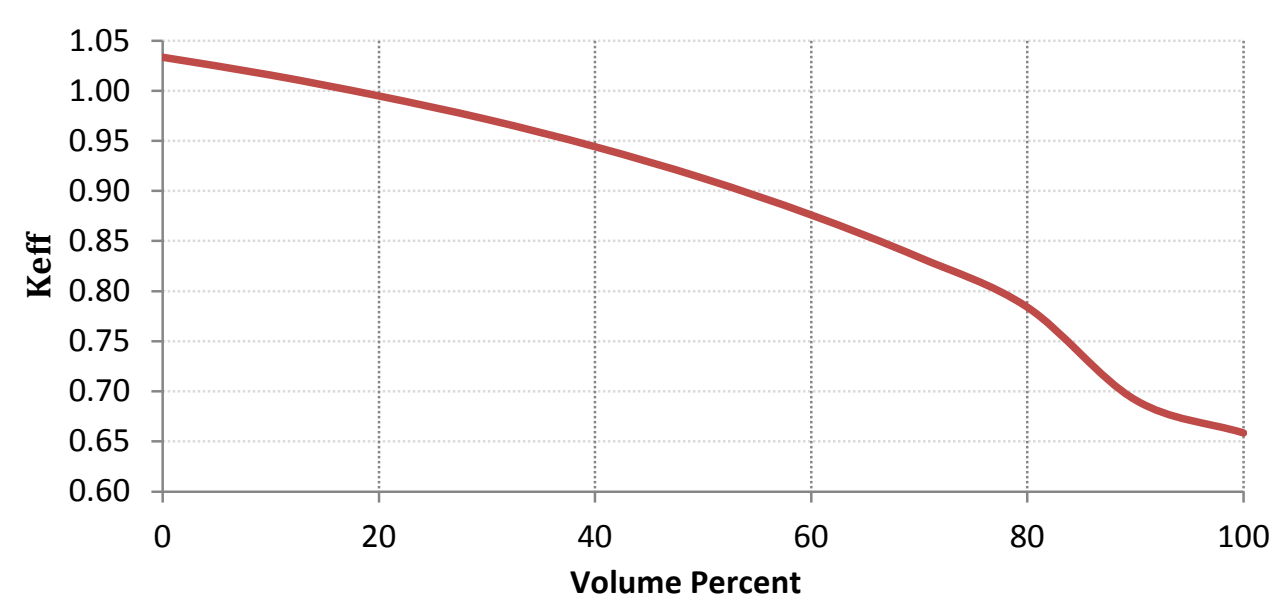

Fig. (9): Changes of the effective multiplication factor in different concentrations of heavy water

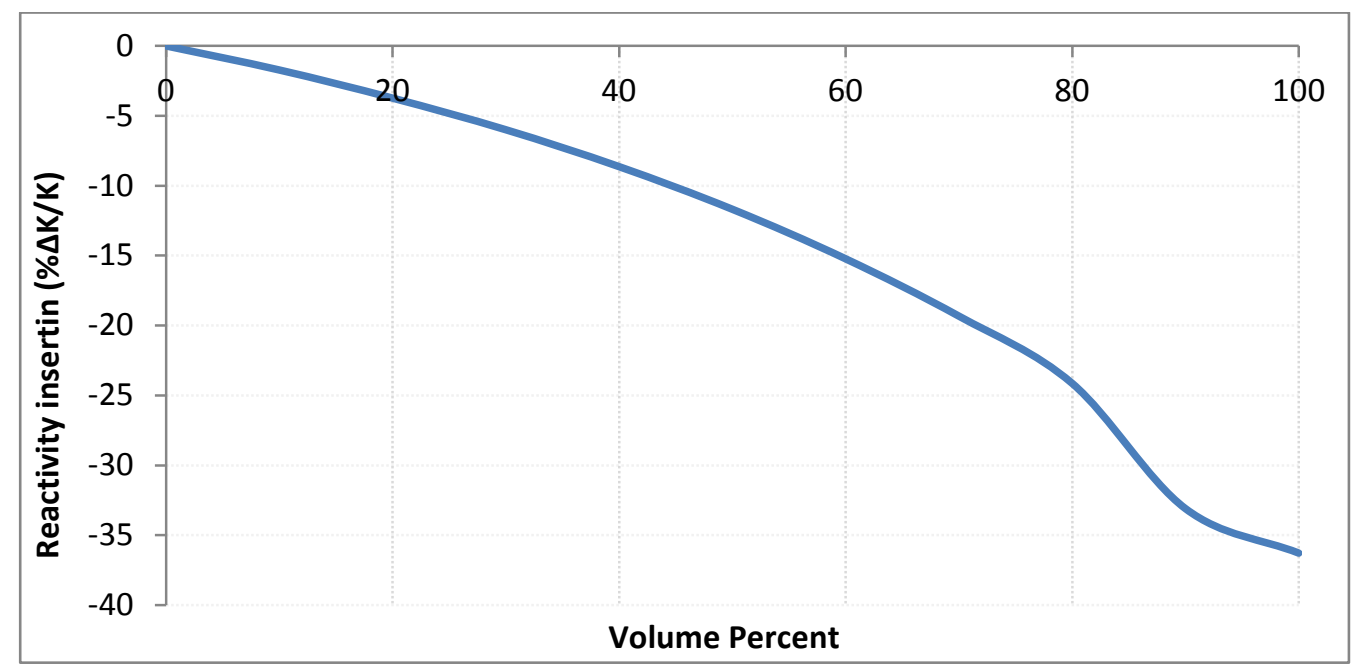

Fig. (10): Reactivity insertion in different concentrations of heavy water

\section{Conclusion}

The main goal of this study is to predict the neutronic behavior of heavy water injection as a coolant in the emergency core cooling system (ECCS). Although heavy water involves a very low absorption cross-section compared to light water, it has a lower diffusion cross-section. Furthermore, the diffusion length of thermal neutrons in heavy water, due to lower absorption, is several times as large as that of light water. If heavy water is injected into the reactor without any dimensional changes, because fast neutrons fail to pass a desired distance along the moderator to be converted into a thermal state, this phenomenon would lead to the hardening of neutron spectra and their shift toward high-energy neutrons.
In fact, under such conditions, neutrons would lose the opportunity to be thermalized. With the hardening of neutron spectra, neutrons become more likely to escape, and generally the impact left on the reactor core by the heavy water injection would remain as negative reactivity. As a result, in an the case of an accident such as LOCA, injecting heavy water into the reactor, besides cooling it down, brings the reactor to a subcritical state; this phenomenon can help control the reactor safer and more reliable than the effect of prevalent emergency light water injection systems.

\section{References}

1- Squarer, D., Schulenberg, T., Struwe, D., Oka, Y., Bittermann, D., Aksan, N., Maráczy, C., KyrkiRajamäki, R., Souyri, A., Dumaz, P., High 
performance light water reactor, Nucl. Eng. Des.; 2003. 221, pp. 167-180

2- US DOE, Nuclear Energy Research Advisory Committee and the Generation IV International Forum, a Technology Roadmap for the Generation IV Nuclear Energy System. 2002.

3- Ammirabile, L.: Studies on supercritical water reactor fuel assemblies using the sub-channel code COBRA-EN. Nucl. Eng. Des. 240; 2010, 3087 3094

4- Ishiwatari, Y., Oka, Y., Koshizuka, S., and Liu, T., Safety Characteristics of the Super LWR Design Concept,” Proc. ICAPP’07, Nice, France; 2007. Paper 7309

5- Lee, J.H., Koshizuka S., Oka, Y., Development of a LOCA Analysis Code for the Supercritical-Pressure Light Water Cooled Reactors," Annals of Nuclear Energy; 1998.Vol. 25 (16), 1341-1361

6- Tashakor, S., Salehi, A. A., Jahanfarnia, G., Abbaspour Tehrani Fard, A., Neutronic analysis of HPLWR fuel assembly cluster, Annals of Nuclear Energy; 2012.50, 38-43

7- Tashakor, S., Salehi, A. A., Jahanfarnia, G., Abbaspour Tehrani Fard, A., Thermal-hydraulic analysis of HPLWR fuel assembly cluster, The Journal of Supercritical Fluids; 2013. 77, 91-99.

8- Tashakor, S., Zarifi, E., Salehi, A. A., Axial enrichment profile in advance nuclear energy power plant at supercritical-pressuresr, Kerntechnik; 2015.80, 541-544.

9- Tashakor, S., neutronic investigation of semi heavy water application in hplwr new flow pattern, CNL Nuclear Review;2016.6(1), 41-45.

10- Tashakor, S., Salehi, A. A., Jahanfarnia, G., Abbaspour Tehrani Fard, A., Variable moderation high performance light water reactor (VMHWR), Annals of Nuclear Energy; 2013.50, 1-5.

11- Siraj-ul-Islam, Ahmad., Nasir, Ahmad., Effect of updated WIMSD libraries on neutron energy spectrum at irradiation site of Pakistan research reactor-1 using 3D modeling. Ann. Nucl. Energy;2005. 32, 521-548.

12- NEA, NEA-1507, WIMSD-5B (98/11), Deterministic Multi-group Reactor Lattice Calculations;1999.

13- Oak ridge national laboratory, RSICC computer code collection (CITATIONLDI2 code);1972.

14- Fowler, T.B., CITATION-LDI2 Nuclear Reactor Core Analysis Code System. CCC-643, Oak Ridge National Laboratory, Oak Ridge, Tennessee;1999

15- Horita, J., Cole, D. R., Stable isotope partitioning in aqueous and hydrothermal systems to elevated temperatures, in Aqueous systems at elevated temperatures and pressures: Physical chemistry in water, steam and hydrothermal solutions, ed. D. A. Palmer, R. Fernández-Prini and A. H. Harvey, Elsevier, Amsterdam; 2004. pp. 277-319. 